\title{
cGMP-stimulated Cyclic Nucleotide Phosphodiesterase Regulates the Basal Calcium Current in Human Atrial Myocytes
}

\author{
Michèle Rivet-Bastide, ${ }^{*}$ Grégoire Vandecasteele, ${ }^{\star}$ Stéphane Hatem, ${ }^{\ddagger}$ Ignacio Verde, ${ }^{\star}$ Agnès Bénardeau, ${ }^{\ddagger}$ \\ Jean-Jacques Mercadier, ${ }^{\ddagger}$ and Rodolphe Fischmeister ${ }^{\star}$ \\ * Laboratoire de Cardiologie Cellulaire et Moléculaire, Institut National de la Santé et de la Recherche Médicale U-446, Université de \\ Paris-Sud, Faculté de Pharmacie, F-92296 Châtenay-Malabry, France; and ${ }^{\ddagger}$ Laboratoire de Cardiologie Moléculaire et Cellulaire, \\ Centre National de la Recherche Scientifique URA 1159, Université de Paris-Sud, Hôpital Marie-Lannelongue, F-92350 Le Plessis \\ Robinson, France
}

\begin{abstract}
EHNA (Erythro-9-[2-hydroxy-3-nonyl]adenine) is a wellknown inhibitor of adenosine deaminase. Recently, EHNA was shown to block the activity of purified soluble cGMPstimulated phosphodiesterase (PDE2) from frog, human, and porcine heart with an apparent $K_{\mathrm{i}}$ value of $\sim 1 \mu \mathrm{M}$ and with negligible effects on $\mathrm{Ca}^{2+}$ /calmodulin PDE (PDE1), cGMP-inhibited PDE (PDE3), and low $K_{\mathrm{m}}$ cAMP-specific PDE (PDE4) (Méry, P.F., C. Pavoine, F. Pecker, and R. Fischmeister. 1995. Mol. Pharmacol. 48:121-130; Podzuweit, T., P. Nennstiel, and A. Muller. 1995. Cell. Signalling. 7:733738). To investigate the role of PDE2 in the regulation of cardiac L-type $\mathrm{Ca}^{2+}$ current $\left(\mathrm{I}_{\mathrm{Ca}}\right)$, we have examined the effect of EHNA on $\mathrm{I}_{\mathrm{Ca}}$ in freshly isolated human atrial myocytes. Extracellular application of 0.1-10 $\mu \mathrm{M}$ EHNA induced an increase in the amplitude of basal $\mathrm{I}_{\mathrm{Ca}}(\sim 80 \%$ at 1 $\mu \mathrm{M})$ without modification of the current-voltage or inactivation curves. The maximal stimulatory effect of EHNA on $I_{\mathrm{Ca}}$ was comparable in amplitude with the maximal effect of isoprenaline $(1 \mu \mathrm{M})$, and the two effects were not additive. The effect of EHNA was not a result of adenosine deaminase inhibition, since $2^{\prime}$-deoxycoformycin (1-30 $\left.\mu \mathrm{M}\right)$, another adenosine deaminase inhibitor with no effect on PDE2, or adenosine (1-10 $\mu \mathrm{M})$ did not increase $\mathrm{I}_{\mathrm{Ca}}$. In the absence of intracellular GTP, the substrate of guanylyl cyclase, EHNA did not increase $\mathrm{I}_{\mathrm{Ca}}$. However, under similar conditions, intracellular perfusion with $0.5 \mu \mathrm{M}$ cGMP produced an $80 \%$ increase in $\mathrm{I}_{\mathrm{Ca}}$. As opposed to human cardiomyocytes, EHNA (1-10 $\mu \mathrm{M})$ did not modify $\mathrm{I}_{\mathrm{Ca}}$ in isolated rat ventricular and atrial myocytes. We conclude that basal $\mathrm{I}_{\mathrm{Ca}}$ is controlled by PDE2 activity in human atrial myocytes. Both PDE2 and PDE3 may contribute to keep the cyclic nu-
\end{abstract}

This paper was presented in abstract form at the XVth World Congress of the International Society for Heart Research in Prague, Czech Republic on 2-7 July 1995.

Address correspondence to Dr. Rodolphe Fischmeister, INSERM U-446, Université de Paris-Sud, Faculté de Pharmacie, 5, Rue J.-B. Clément, F-92296 Châtenay-Malabry Cedex, France. Phone: 33-1-4683-57-71; FAX: 33-1-46-83-54-75; E-mail: fisch@vjf.inserm.fr M. Rivet-Bastide's present address is Laboratoire de Pharmacologie, Faculté de Médecine, 1 Place de Verdun, F-59045 Lille Cedex.

Received for publication 30 July 1996 and accepted in revised form 13 March 1997.

J. Clin. Invest.

(C) The American Society for Clinical Investigation, Inc. 0021-9738/97/06/2710/09 \$2.00

Volume 99, Number 11, June 1997, 2710-2718 cleotides concentrations at minimum in the absence of adenylyl and/or guanylyl cyclase stimulation. (J. Clin. Invest. 1997. 99:2710-2718.) Key words: human cardiac myocytes • calcium channel current - cGMP • cGMP-stimulated phosphodiesterase • EHNA (Erythro-9-[2-hydroxy-3-nonyl]adenine $\cdot$ adenosine deaminase

\section{Introduction}

Hormonal regulation of cardiac function often involves a modification of adenylyl or guanylyl cyclase activity, which leads to changes in the intracellular cAMP or cGMP concentrations and to subsequent alterations in the degree of cAMP- or cGMPdependent protein phosphorylation. One of the best illustrated examples of such a regulation is the $\beta$-adrenergic stimulation of the cardiac L-type $\mathrm{Ca}^{2+}$ channel current $\left(\mathrm{I}_{\mathrm{Ca}}\right)^{1}$ and contraction (1-3). However, the intracellular concentration of cyclic nucleotides is not only regulated at the level of synthesis but also at the level of degradation. The latter is accounted for by cyclic nucleotide phosphodiesterases (PDEs), which break down cAMP and cGMP into 5'-AMP and 5'-GMP, respectively, and thereby limit the degree of protein phosphorylation (4). Like adenylyl and guanylyl cyclases, PDEs are potential targets for hormonal regulation $(4,5)$. Four different PDEs have been shown to coexist in the heart muscle $(4,6):(a)$ a $\mathrm{Ca}^{2+} /$ calmodulin-dependent PDE (PDE1); (b) a cGMP-stimulated PDE (PDE2); (c) a cGMP-inhibited PDE (PDE3); and (d) a low $K_{\mathrm{m}}$, cAMP-specific PDE (PDE4). Studies of the regulation of $\mathrm{I}_{\mathrm{Ca}}$ by the different PDEs have provided information about the functional importance of PDE2, PDE3, and PDE4. Inhibitors of PDE3 (e.g., milrinone) or PDE4 (e.g., rolipram, Ro 20-1724) potentiate $\mathrm{I}_{\mathrm{Ca}}$ response to the $\beta$-adrenergic agonist isoprenaline $(7,8)$. In human atrial cells, PDE3 inhibition with milrinone increases $\mathrm{I}_{\mathrm{Ca}}$ even in the absence of a prestimulation with isoprenaline suggesting a higher basal adenylyl cyclase activity in this tissue (9). PDE3 inhibition can also be achieved via intracellular cGMP perfusion (in guinea pig ventricular myocytes $[8,10]$, but not in rat [11] or frog ventricular myocytes $[12,13])$, or via activation of guanylyl cyclase by nitric oxide (NO) donors $(9,14)$, and this also results in an increase in $\mathrm{I}_{\mathrm{Ca}}$ (for review see reference 15). Until now, however, involvement of PDE2 activity in the regulation of $\mathrm{I}_{\mathrm{Ca}}$ has only been resolved in frog ventricular cells. In this preparation, intracellular application of cGMP reduces isoprenaline- or

1. Abbreviations used in this paper: DCF, $2^{\prime}$-deoxycoformicin (Pentostatin); EHNA, Erythro-9-[2-hydroxy-3-nonyl]adenine; $\mathrm{I}_{\mathrm{Ca}}$, L-type calcium current; PDE, phosphodiesterase; PDE1, $\mathrm{Ca}^{2+} /$ calmodulindependent PDE; PDE2, cGMP-stimulated PDE; PDE3, cGMP-inhibited PDE; PDE4, low $K_{\mathrm{m}}$, cAMP-specific PDE; NO, nitric oxide. 
cAMP-stimulated $\mathrm{I}_{\mathrm{Ca}}$ while it has no effect on basal $\mathrm{I}_{\mathrm{Ca}}$ or on $\mathrm{I}_{\mathrm{Ca}}$ that has been prestimulated by the nonhydrolyzable cAMP analogue 8Br-cAMP $(12,13,15)$. However, the absence of a selective inhibitor of PDE2 has so far limited our knowledge of its functional role in the heart, particularly in humans.

Recently, a selective inhibitor of PDE2, EHNA (Erythro9-[2-hydroxy-3-nonyl]adenine), has been described in frog (16), pig, and human myocardium (17). This adenine derivative was initially designed to inhibit adenosine deaminase activity (18), which it does in the nanomolar range of concentrations. However, EHNA exerts several biochemical effects that are not readily explained on the basis of adenosine deaminase inhibition (see references in 17). Interestingly, EHNA inhibits the cardiac purified soluble PDE2 isoform with an $\mathrm{IC}_{50}$ of 1-5 $\mu \mathrm{M}$ but does not significantly affect other cardiac PDE isoforms at concentrations of up to $30-100 \mu \mathrm{M}(16,17)$. Inhibitory effects of EHNA on PDE2 activity have also been obtained in a number of noncardiac cells, such as thymocytes (19), vascular endothelial (20) and smooth muscle cells (21), and PC12 cells (21). Although the classical inhibitory effect of EHNA on adenosine deaminase limits the selectivity of the drug with respect to PDE2, this compound has already proven to be a useful tool in investigating the role of PDE2 in various cell functions. For instance, inhibition of PDE2 by EHNA reduces the permeability of porcine pulmonary artery endothelial cells (20), attenuates the cAMP metabolism changes that follow the ligation of the T cell antigen receptor in murine thymocytes (19), or reduces the pulmonary vasoconstriction that follows a hypoxic challenge in the perfused rat lung (21). In the heart, the most recognized effect of EHNA is to behave as a cardioprotective agent against ischemia/reperfusion injury (for review see reference 22). This effect is generally attributed to the inhibition of adenosine deaminase, leading to an increase in adenosine levels and/or to a decrease in the generation of free radicals (23). However, EHNA also inhibits PDE2 activity in intact isolated cardiac myocytes, and, by doing so, antagonizes those effects of NO donors or cGMP that are mediated by this enzyme (16). For instance, in frog ventricular myocytes, EHNA fully reverses the inhibitory effect of the NO donors 3-morpholino-sydnonymine (SIN-1) or sodium nitroprusside (SNP) on $\mathrm{I}_{\mathrm{Ca}}(16)$.

Little is known about the role of cGMP and the presence of its putative targets in the human heart. However, cGMP might be involved in the development of certain cardiac pathologies. For instance, in dilated cardiomyopathies, an increased synthesis of the atrial natriuretic peptide (ANP) and NO has been shown, and both substances activate cGMP production (2426). In addition, we recently showed that the NO donor SIN-1 upregulates $\mathrm{I}_{\mathrm{Ca}}$ in human atrial myocytes, and that this effect was likely mediated by a cGMP inhibition of PDE3 (9). To gain insight into the possible role of PDE2 in the regulation of $\mathrm{I}_{\mathrm{Ca}}$ in this preparation, we have now examined the effects of EHNA on the L-type calcium current in whole-cell patchclamped freshly isolated human atrial myocytes.

\section{Methods}

Surgery. All protocols for obtaining human cardiac tissue were approved by the ethics committee of our institution (Groupe de Réflexion sur l'Ethique Biomédicale de Bicêtre, Hôpital de Bicêtre, Université de Paris-Sud). Specimens of right atrial appendages were obtained from 53 patients (aged 4-79 yr) undergoing heart surgery for congen- ital defects, coronary artery diseases, or valve replacement at the Hôpital Marie-Lannelongue (Le Plessis-Robinson, France). Most patients received a pharmacological pretreatment (Ca-channel blockers, digitalis, $\beta$-adrenergic antagonists, diuretics, ACE inhibitors, NO donors, and/or antiarrhythmic drugs). In addition, all patients received sedatives, anesthesia, and antibiotics. 14 patients had no treatment known to possess cardiovascular effects. However, we found no obvious correlation between the calcium current density or the effects on $\mathrm{I}_{\mathrm{Ca}}$ of the drugs tested here and the therapy received (if any) by the patient. Dissociation of the cells was realized immediately after surgery.

Human atrial cell dissociation. Myocytes were isolated as described previously $(9,27)$ with some modifications. Briefly, after the excision of the atrial tissue, the tissue was cut up and washed in a calcium-free Tyrode solution supplemented with $30 \mathrm{mM}$ 2,3-butanedionemonoxine for $10 \mathrm{~min}$ and then incubated in the same solution containing $40 \mathrm{IU} / \mathrm{ml}$ of collagenase, $15 \mathrm{IU} / \mathrm{ml}$ of protease, and $5 \mathrm{mg} / \mathrm{ml}$ of BSA for $30 \mathrm{~min}$. The solution was then replaced by fresh enzymatic solution containing only collagenase for 15-60 min until a satisfactory cell yield was obtained. All steps were carried out at $37^{\circ} \mathrm{C}$, with continuous gassing with $95 \% \mathrm{O}_{2}$ and $5 \% \mathrm{CO}_{2}$. The cell suspension was filtered and centrifuged, and the pellet was resuspended in DME supplemented with $10 \%$ FCS, nonessential amino acids, $1 \mathrm{nM}$ insulin, and antibiotics (penicillin, $100 \mathrm{IU} / \mathrm{ml}$ and streptomycin, $0.1 \mu \mathrm{g} / \mathrm{ml}$ ). For patch-clamp experiments, 100-200 $\mu \mathrm{l}$ of this cell suspension was put in a petri dish containing control external solution.

Rat ventricular and atrial cell dissociation. Rat cardiomyocytes were obtained by retrograde perfusion from hearts of male Wistar rats (180-220 g) as described previously (28) with slight modifications. Briefly, the rats were subjected to anesthesia by intraperitoneal injection of urethane and hearts were excised rapidly. The ionic composition of the solutions were as follows: Ca-free Tyrode solution (mM): $\mathrm{NaCl} 117 ; \mathrm{KCl}$ 5.7; $\mathrm{NaHCO}_{3} 4.4 ; \mathrm{KH}_{2} \mathrm{PO}_{4} 1.5 ; \mathrm{MgCl}_{2}$ 1.7; Hepes 21.1; creatine 10; D-glucose 11.7; taurine 20; $\mathrm{pH}$ adjusted to 7.1 with $\mathrm{NaOH}$ at room temperature. For enzymatic dissociation, $1 \mathrm{mg} / \mathrm{ml}$ collagenase A (Boehringer Mannheim, Mannheim, Germany) and $300 \mu \mathrm{M}$ EGTA were added to the Ca-free solution, and the free Ca concentration was then adjusted to $20 \mu \mathrm{M}$. The hearts were perfused retrogradely at a constant flow of $6 \mathrm{ml} / \mathrm{min}$ and at $37^{\circ} \mathrm{C}$ by an oxygenated Ca-free Tyrode solution during $5 \mathrm{~min}$ followed by $1 \mathrm{~h}$ of perfusion at $4 \mathrm{ml} / \mathrm{min}$ with the same solution containing collagenase. The ventricles and atria were then separated. Ventricles were chopped finely and agitated gently to dissociate individual cells. The resulting cell suspension was filtered and the cells were settled down. The supernatant was discarded and cells resuspended four more times in Tyrode solution containing a progressively increasing calcium concentration. Atrias were cut into small pieces, then further digested at $37^{\circ} \mathrm{C}$ in an oxygenated solution containing collagenase $(0.178 \mathrm{IU} / \mathrm{ml})$, protease $(1.06 \mathrm{IU} / \mathrm{ml})$, and BSA $(1 \mathrm{mg} / \mathrm{ml})$ with continuous gentle agitation. After $20 \mathrm{~min}$, the cells were settled down and the supernatant was removed. The cells were then resuspended as described above for ventricular myocytes. Both atrial and ventricular myocytes were maintained at $37^{\circ} \mathrm{C}$ until use.

Electrophysiological experiments. The whole-cell configuration of the patch-clamp technique (29) was used to record the high-threshold calcium current $\left(\mathrm{I}_{\mathrm{Ca}}\right)$ on $\mathrm{Ca}^{2+}$-tolerant human atrial and rat ventricular and atrial myocytes. In the routine protocols, the cells were depolarized every $8 \mathrm{~s}$ from a holding potential of $-80 \mathrm{mV}$ to $0 \mathrm{mV}$ for 200 or $400 \mathrm{~ms}$ after a short prepulse $(50 \mathrm{~ms})$ to $-50 \mathrm{mV}$. The prepulse, together with the application of tetrodotoxin $(30 \mu \mathrm{M})$, was used to eliminate fast sodium currents. In some experiments all sodium ions were substituted for tetraethylammonium ions to prevent sodium currents, without any detectable incidence on the results compared to those obtained with sodium-containing solutions. $\mathrm{K}^{+}$currents were blocked by replacing all $\mathrm{K}^{+}$ions with intracellular $\mathrm{Cs}^{+}$and extracellular $\mathrm{Cs}^{+}$or tetraethylammonium ions $\left(\mathrm{TEA}^{+}\right)$. For the determination of current-voltage relationships for $\mathrm{I}_{\mathrm{Ca}}$ (see Fig. $2 A$ ) and $\mathrm{I}_{\mathrm{Ca}}$ inactivation curve (see Fig. $2 \mathrm{~B}$ ), a double-pulse voltage-clamp protocol was used (9). Briefly, every $4 \mathrm{~s}$, the membrane potential of the cell, which 
was normally maintained at its holding value of $-80 \mathrm{mV}$, experienced the following sequence of events: $-50 \mathrm{mV}$ for $10 \mathrm{~ms}$, different potentials values ranging from -100 to $+100 \mathrm{mV}$ for $200 \mathrm{~ms} ;-50 \mathrm{mV}$ for 3 $\mathrm{ms}$, and $0 \mathrm{mV}$ for $200 \mathrm{~ms}$ (see inset, Fig. 2 B). Voltage-clamp protocols were generated by a challenger/09-VM programmable function generator (Kinetic Software, Atlanta, GA). The cells were voltageclamped using a patch-clamp amplifier (model RK-400; Bio-Logic, Claix, France). Currents were sampled at a frequency of $10 \mathrm{kHz}$ using a 12-bit analog-to-digital converter (DT2827; Data Translation, Marlboro, MA) connected to a PC compatible computer (386/33 Systempro; Compaq Computer Corp., Houston, TX). All experiments were done at room temperature $\left(19-25^{\circ} \mathrm{C}\right)$.

Solutions. Control external solution contained $(\mathrm{mM}): 107.1 \mathrm{NaCl}$, 10 Hepes, $40 \mathrm{CsCl}, 4 \mathrm{NaHCO}_{3}, 0.8 \mathrm{NaH}_{2} \mathrm{PO}_{4}, 1.8 \mathrm{CaCl}_{2}, 1.8 \mathrm{MgCl}_{2}$, 5 D-glucose, 5 sodium pyruvate, 0.03 tetrodotoxin, $\mathrm{pH} 7.4$, adjusted with $\mathrm{NaOH}$. TEA external solution consisted of (mM): 136.9 TEACl, 10 Hepes, 5 D-glucose, $1.8 \mathrm{CaCl}_{2}, 1.8 \mathrm{MgCl}_{2}$, $\mathrm{pH} 7.4$, adjusted with TEAOH. Control or drug-containing solutions were applied to the exterior of the cell by placing the cell at the opening of $250-\mu \mathrm{m}$ inner diameter capillary tubings flowing at a rate of $\sim 10 \mu \mathrm{l} / \mathrm{min}$. Patch electrodes $(0.8-1.5 \mathrm{M} \Omega)$ were filled with control internal solution that contained (mM): $119.8 \mathrm{CsCl}, 5$ EGTA (acid form), $4 \mathrm{MgCl}_{2}, 5$ creatine phosphate disodium salt, $3.1 \mathrm{Na}_{2} \mathrm{ATP}, 0.42 \mathrm{Na}_{2}$-GTP, 10 Hepes, 62 $\mu \mathrm{M} \mathrm{CaCl}_{2}$ (pCa 8.5), $\mathrm{pH} 7.3$, adjusted with $\mathrm{CsOH}$. In some experiments (see Fig. 5), a 0-GTP-containing internal solution was used which was obtained by simply omitting $\mathrm{Na}_{2}$-GTP from the control internal solution. A change in the intracellular solution (see Fig. 6) was made possible by the use of a perfusion system that allowed us to modify the solution at the tip of the patch electrode during the course of a whole-cell patch-clamp recording $(12,13)$.

Materials. Collagenase type IV and protease type XXIV used for human atrial cell dissociation were purchased from Sigma (L'Isle d'Abeau Chesnes, France). Collagenase type A for rat cardiac myocyte dissociation and FCS were from Boehringer Mannheim. DME was obtained from GIBCO-BRL (Gaithersburg, MD). 2'-deoxycoformycin (DCF) was from Parke-Davis (Ann Arbor, MI). Tetrodotoxin was from Latoxan (Rosans, France). All other drugs, including EHNA, were from Sigma. All drugs were dissolved in ionic aqueous solutions.

Data analysis. The maximal amplitude of $\mathrm{I}_{\mathrm{Ca}}$ was measured as the difference between the peak inward current and the leak current $\left(\mathrm{I}_{400}\right)$, which was the current amplitude at the end of the 400-ms duration pulse (9). Currents were not compensated for capacitive and leak currents. Cell membrane capacitance and series resistances were measured by exponential analysis of current responses to $1-\mathrm{mV}$ step changes in membrane potential. Membrane capacitance was $59.6 \pm 4.6$ $\mathrm{pF}$ (mean $\pm \mathrm{SEM}$ ) and series resistance was $4.3 \pm 0.6 \mathrm{M} \Omega$ for human atrial cells $(n=28), 174.7 \pm 8.9 \mathrm{pF}$ and $4.6 \pm 0.4 \mathrm{M} \Omega$ for rat ventricular cells $(n=24)$, and $46.1 \pm 4.9 \mathrm{pF}$ and $6.5 \pm 0.7 \mathrm{M} \Omega$ for rat atrial cells $(n=10)$. The on-line analysis was made possible by programming a PC compatible computer in Pascal language to determine each depolarization, peak, and steady state current value.

The results are expressed as mean \pm SEM. In each experimental condition, the effects of the drugs tested on $\mathrm{I}_{\mathrm{Ca}}$ are expressed as percent change with respect to the values of the current under basal conditions, i.e., in the absence of any hormonal stimulation. The variations in $\mathrm{I}_{\mathrm{Ca}}$ induced by EHNA were tested for statistical significance by Student's $t$ test.

\section{Results}

$\mathrm{I}_{\mathrm{Ca}}$ was recorded in human atrial myocytes using the whole-cell configuration of the patch-clamp technique (29). Basal $\mathrm{I}_{\mathrm{Ca}}$ amplitude was measured 3-15 min after patch break to allow for equilibration between intracellular and pipette solutions. Basal $\mathrm{I}_{\mathrm{Ca}}$ amplitude at $0 \mathrm{mV}$ membrane potential was on average 160.2 $\pm 18.2 \mathrm{pA}$ and $\mathrm{I}_{\mathrm{Ca}}$ density, which represents the ratio of $\mathrm{I}_{\mathrm{Ca}}$ amplitude to membrane capacitance, was $2.67 \pm 0.28 \mathrm{pA} /$ $\mathrm{pF}(n=28)$. As in our previous study $(9), \mathrm{I}_{\mathrm{Ca}}$ densities showed a large scatter between different patients and between individual cells from the same patient, with no obvious correlation with the diagnosis, sex, age, or pretreatment of the patients. Fig. 1 shows an experiment in which three different concentrations of EHNA $(0.1,0.3$, and $1 \mu \mathrm{M})$ were tested on a human atrial myocyte. EHNA was applied extracellularly and $\mathrm{I}_{\mathrm{Ca}}$ amplitude was measured at $0 \mathrm{mV}$ membrane potential. As shown in Fig. $1 \mathrm{~B}$, application of $0.1 \mu \mathrm{M}$ EHNA produced a strong $(70 \%)$ stimulation of basal $\mathrm{I}_{\mathrm{Ca}}$ amplitude. When a threefold higher concentration $(0.3 \mu \mathrm{M})$ was applied, $\mathrm{I}_{\mathrm{Ca}}$ almost doubled in amplitude compared to its control value. The stimulatory effect of EHNA was completely and quickly reversible upon washout of the drug. After $\mathrm{I}_{\mathrm{Ca}}$ returned to control level, the cell was challenged again with a third concentration $(1 \mu \mathrm{M})$ of EHNA, which produced a second large and reversible increase in $\mathrm{I}_{\mathrm{Ca}}$. The individual current traces in Fig. $1 A$ show that the stimulatory effect of EHNA was not accompanied by any significant modification in the kinetics of $\mathrm{I}_{\mathrm{Ca}}$. This suggests that EHNA did not modify the voltage dependence of the Ca channel gating. To examine this aspect further, the effect of EHNA was investigated on the $\mathrm{I}_{\mathrm{Ca}}$ current-voltage (Fig. $2 A$ ) and inactivation (Fig. $2 B$ ) relationships. The U-shape of both curves for basal $\mathrm{I}_{\mathrm{Ca}}$ (open rectangles, Fig. 2, $A$ and $B$ ), as well as their respective positions on the voltage axis, are characteristic of the high-threshold L-type Ca current in this preparation (9).
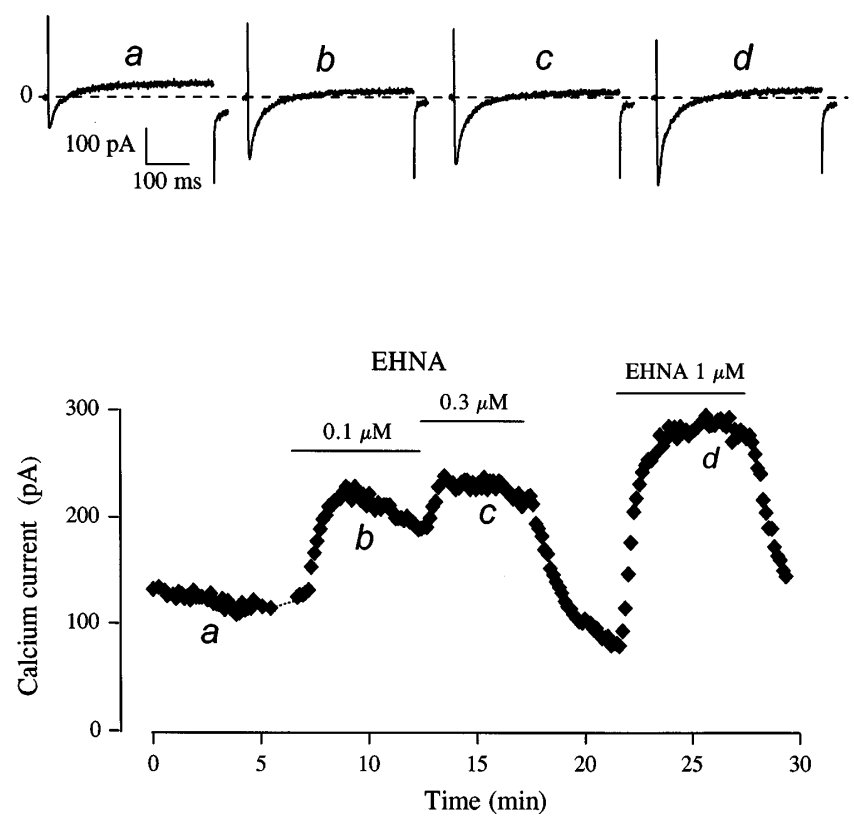

Figure 1. Time course of the effects of EHNA on basal $\mathrm{I}_{\mathrm{Ca}}$ in an isolated human atrial myocyte. Each symbol corresponds to a measure of $\mathrm{I}_{\mathrm{Ca}}$ at $0 \mathrm{mV}$ obtained every $8 \mathrm{~s}$. The cell was first superfused with control solution and then exposed to increasing concentrations of EHNA $(0.1,0.3$, and $1 \mu \mathrm{M})$ during the periods indicated by the solid lines. After the applications of 0.3 and $1 \mu \mathrm{M}$ EHNA, the cell returned to control solution. The individual current traces shown on the upper part were obtained at the times indicated by the corresponding letters in the bottom graph. Dotted line, zero current level. 


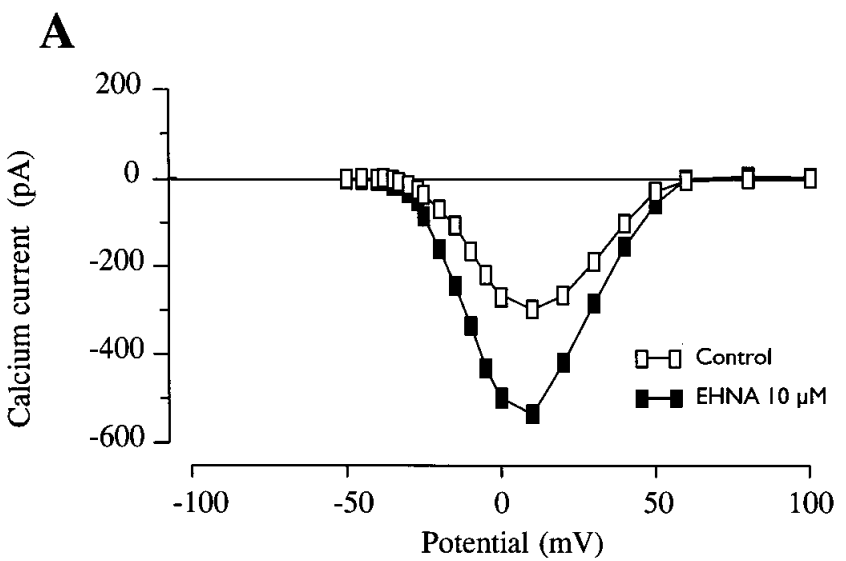

B

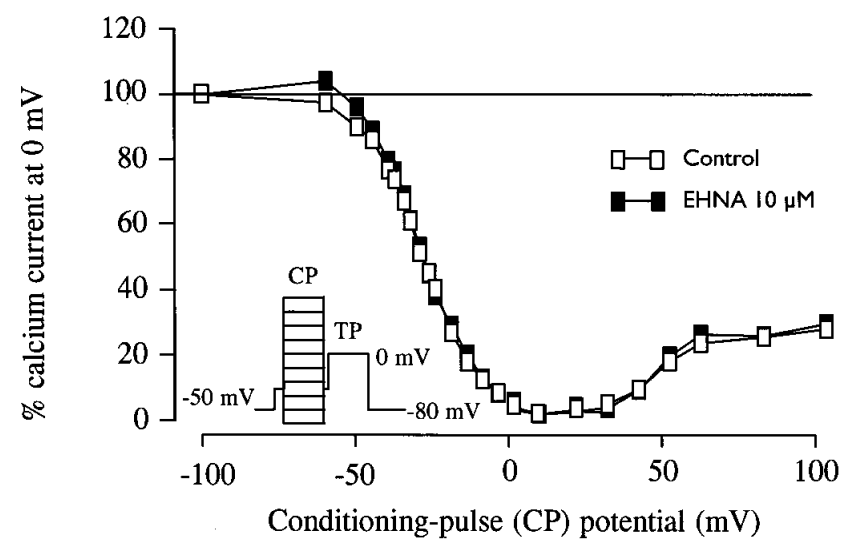

Figure 2. Voltage-dependence of the stimulatory effect of EHNA on basal $\mathrm{I}_{\mathrm{Ca}}$ in a human atrial myocyte. Current-voltage relationship $(A)$ and inactivation curve of $\mathrm{I}_{\mathrm{Ca}}(B)$ in control condition (open rectangles) and in the presence of $10 \mu \mathrm{M}$ of EHNA (filled rectangles). Inactivation curves were obtained using the double-pulse protocol as indicated in the inset (see also Methods).

As shown, $10 \mu \mathrm{M}$ EHNA increased $\mathrm{I}_{\mathrm{Ca}}$ by a similar amount at every membrane potential (Fig. 2 A, filled rectangles) and did not modify the inactivation curve of the current (Fig. $2 B$ ).

Fig. 3 summarizes the results of several experiments performed with EHNA in human atrial myocytes. At all three concentrations tested $(0.1,1$, and $10 \mu \mathrm{M})$, EHNA produced a significant stimulation of $\mathrm{I}_{\mathrm{Ca}}$. For technical reasons, not all three concentrations could be tested systematically on the same myocytes, so that the results do not show a clear dose dependency in the effects of EHNA. However, each time two concentrations of the drug were examined in the same cell, $1 \mu \mathrm{M}$ EHNA increased $\mathrm{I}_{\mathrm{Ca}}$ to a higher level than $0.1 \mu \mathrm{M}$ (e.g., see Fig. 1), and $10 \mu \mathrm{M}$ EHNA either increased $\mathrm{I}_{\mathrm{Ca}}$ further or had no additional effect on $\mathrm{I}_{\mathrm{Ca}}$ that had been increased by a $1 \mu \mathrm{M}$ concentration of the drug. The effect of $1 \mu \mathrm{M}$ isoprenaline, a nonselective $\beta$-adrenergic agonist, was also examined in these cells. Fig. 3 shows that the maximal stimulatory effect of EHNA on $\mathrm{I}_{\mathrm{Ca}}$ is comparable to that produced by a saturating concentration of isoprenaline. Furthermore, EHNA $(10 \mu \mathrm{M})$ produced no additional effect on $\mathrm{I}_{\mathrm{Ca}}$ which had been prestimulated by isoprenaline (Fig. 3).

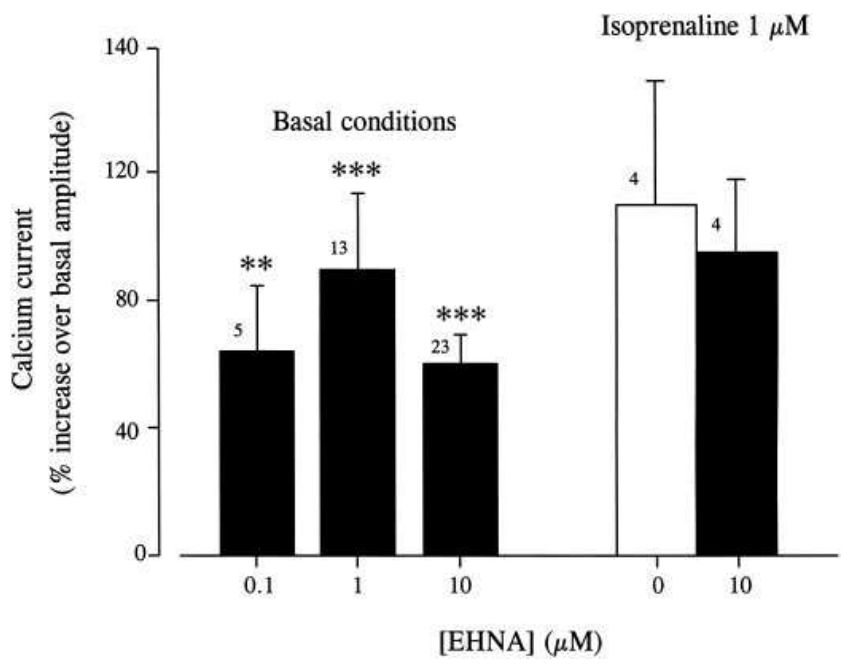

Figure 3. Summary of the effects of EHNA on basal $\mathrm{I}_{\mathrm{Ca}}$ in human atrial myocytes. The effects of $0.1,1$, and $10 \mu \mathrm{M}$ of EHNA are shown on basal $\mathrm{I}_{\mathrm{Ca}}$ and compared to the effect of $1 \mu \mathrm{M}$ isoprenaline. The effect of $10 \mu \mathrm{M}$ EHNA in the presence of isoprenaline is also shown. The bars indicate the means and the lines the SEM of the number of experiments indicated near the bars. Statistical significant differences from control $\mathrm{I}_{\mathrm{Ca}}$ amplitude, $* * P<0.05 ; * * * P<0.005$.

Since EHNA produced a similar maximal increase in $\mathrm{I}_{\mathrm{Ca}}$ as isoprenaline, and both compounds did not produce any additional effect on $\mathrm{I}_{\mathrm{Ca}}$ when used simultaneously (Fig. 3), the most likely mechanism for the stimulatory effect of EHNA on $\mathrm{I}_{\mathrm{Ca}}$ is an increase in cAMP concentration and a subsequent activation of $\mathrm{I}_{\mathrm{Ca}}$ by cAMP-dependent phosphorylation. However, since EHNA was shown to be an adenosine deaminase inhibitor (18), it was necessary to examine the respective roles of PDE2 and adenosine deaminase inhibition in the stimulatory effect of EHNA on $\mathrm{I}_{\mathrm{Ca}}$ in human atrial myocytes. To do this, we first investigated the effect of DCF, a compound without effect on PDE2 (17) but with an even higher adenosine deaminase inhibiting potency as compared to EHNA (references in $20)$. Since, at a $2 \mu \mathrm{M}$ concentration, DCF was shown recently to fully inhibit adenosine deaminase activity in isolated rabbit cardiac myocytes (30), we used a somewhat similar concentration $(3 \mu \mathrm{M})$ in most of our experiments. However, three other concentrations of DCF (10 nM, and 1 and $30 \mu \mathrm{M})$ were tested in two to three cells with no significant differences in results (data not shown). In the experiment shown in Fig. 4, application of $10 \mu \mathrm{M}$ EHNA produced a large increase in $\mathrm{I}_{\mathrm{Ca}}$. After washout of the drug, the current returned to control amplitude and, a few minutes later, the cell was exposed to $3 \mu \mathrm{M}$ DCF. As shown, DCF had no stimulatory effect on $\mathrm{I}_{\mathrm{Ca}}$, but rather slightly decreased the current. After washout of DCF, the cell was challenged again with EHNA $(10 \mu \mathrm{M})$, which was still able to produce a clear stimulation in $\mathrm{I}_{\mathrm{Ca}}$. In a total of four similar experiments in which EHNA $(10 \mu \mathrm{M})$ produced a clear stimulatory effect on $\mathrm{I}_{\mathrm{Ca}}, 3 \mu \mathrm{M}$ DCF reduced $\mathrm{I}_{\mathrm{Ca}}$ by $15.5 \pm 20.5 \%$. The participation of adenosine deaminase in the stimulatory effect of EHNA was further examined by investigating the effect of a direct application of adenosine on $\mathrm{I}_{\mathrm{Ca}}$. Application of adenosine did not mimic the effects of EHNA on $\mathrm{I}_{\mathrm{Ca}}$. On the contrary, 1 and $10 \mu \mathrm{M}$ adenosine induced erratic 


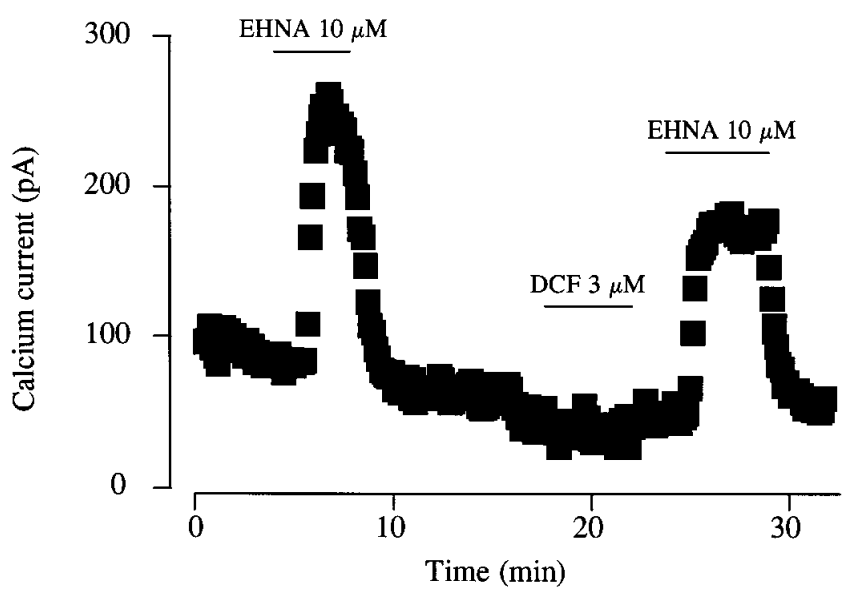

Figure 4. Comparative effects of EHNA and DCF on basal $\mathrm{I}_{\mathrm{Ca}}$ in a human atrial myocyte. Each symbol corresponds to a measure of $\mathrm{I}_{\mathrm{Ca}}$ at $0 \mathrm{mV}$ obtained every $8 \mathrm{~s}$. The cell was first superfused with control solution and then exposed to EHNA $(10 \mu \mathrm{M})$ or DCF $(3 \mu \mathrm{M})$ during the periods indicated by the solid lines.

variations in $\mathrm{I}_{\mathrm{Ca}}$ which did not reach statistical significance (1 $\mu \mathrm{M}$ adenosine: $+15.6 \pm 28.6 \%, n=8 ; 10 \mu \mathrm{M}$ adenosine: $-17.3 \pm 4.1 \%, n=4)$. Thus, inhibition of adenosine deaminase is unlikely to participate in the stimulatory effect of EHNA on $\mathrm{I}_{\mathrm{Ca}}$.

These results suggest that EHNA may affect $\mathrm{I}_{\mathrm{Ca}}$ through its inhibitory effect on PDE2 $(16,17)$. Since PDE2 may hydrolyze both cAMP and cGMP, and its activity is stimulated by low concentrations of cGMP binding to an allosteric site (4), we tested the possibility that a basal production of cGMP is responsible for a meaningful PDE2 activity in human atrial myocytes. Guanylyl cyclases synthesize cGMP from GTP, with a $K_{\mathrm{m}}$ of $100-150 \mu \mathrm{M}(31,32)$. Thus, elimination of GTP from the intracellular solution should abolish, or at least diminish, endogenous cGMP production. Such an approach was already used in human atrial cells to examine the role of guanylyl cyclase activity in the effect of the atrial natriuretic peptide on $\mathrm{I}_{\mathrm{Ca}}$ (33). Therefore, we reexamined the effect of EHNA on $\mathrm{I}_{\mathrm{Ca}}$ in human atrial myocytes in the absence of GTP in the patch pipette solution. In 5 out of 27 cells without intracellular GTP, 10 $\mu \mathrm{M}$ EHNA produced either no effect or a small increase in $\mathrm{I}_{\mathrm{Ca}}$ that did not reach statistical significance (Fig. 5). However, in the remaining 22 cells, EHNA $(10 \mu \mathrm{M})$ always reduced $\mathrm{I}_{\mathrm{Ca}}$ (Fig. 5). We verified that the capacity of EHNA to stimulate $\mathrm{I}_{\mathrm{Ca}}$ in the presence of a routine $(420 \mu \mathrm{M})$ GTP concentration was preserved in the same series of experiments (Fig. 5). It should be noted that the absence of GTP in the dialyzing solution did not reduce the GTP concentration, at least near the membrane, to a sufficient extent to blunt the receptor-mediated activation of GTP-binding proteins. Indeed, even in the absence of exogenous GTP, isoprenaline $(1 \mu \mathrm{M})$ was still able to produce a strong stimulation of $\mathrm{I}_{\mathrm{Ca}}$ (Fig. 5). This was not unexpected since the $K_{\mathrm{m}}$ of G proteins for GTP is $\sim 0.3 \mu \mathrm{M}$ (34), i.e., almost three orders of magnitude lower than that of guanylyl cyclases $(31,32)$.

The above results demonstrate that GTP is required to support a basal activity of PDE2. The most likely explanation for this is that GTP is converted to cGMP, which then stimulates

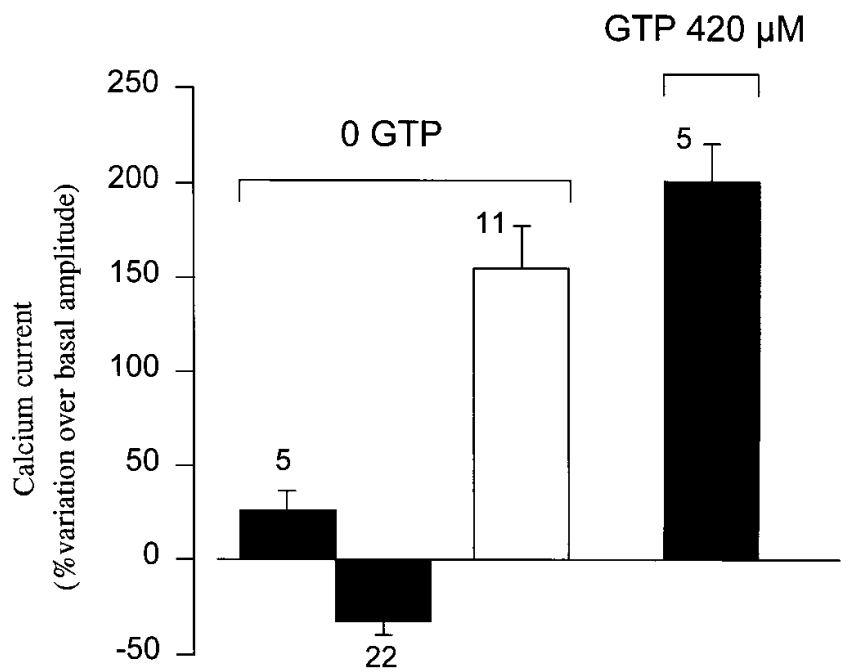

Figure 5. Summary of the effects of EHNA in the absence and presence of intracellular GTP on basal $\mathrm{I}_{\mathrm{Ca}}$ in human atrial myocytes. The effects of $0.1 \mu \mathrm{M}$ of EHNA (filled bars) were examined in human atrial myocytes that were dialyzed with a patch pipette solution that contained either no GTP ( 0 GTP $)$ or $420 \mu \mathrm{M}$ GTP (see Methods). The data obtained in 0 GTP were divided in experiments that showed either inhibitory effects ( 22 cells) or stimulatory effects ( 5 cells) of EHNA. These data are compared with the effect of $1 \mu \mathrm{M}$ isoprenaline (open bar). The bars indicate the means and the lines the SEM of the number of experiments indicated near the bars.

PDE2 activity. However, we have shown earlier that basal $\mathrm{I}_{\mathrm{Ca}}$ is also controlled by PDE3, a cGMP-inhibited PDE, in human atrial myocytes (9). So, an obvious question is: What are the respective contributions of PDE2 and PDE3 in the control of $\mathrm{I}_{\mathrm{Ca}}$ when cGMP level rises inside the cell? To address this question, we examined the effect of an intracellular perfusion with cGMP in human atrial myocytes. The myocytes were dialyzed with a 0 GTP-containing internal solution in order to abolish basal cGMP production by the cells. As shown in Fig. 6 , intracellular perfusion of a human atrial myocyte with 0.5 $\mu \mathrm{M}$ cGMP produced a net stimulation of basal $\mathrm{I}_{\mathrm{Ca}}$. The stimulatory effect of cGMP on $\mathrm{I}_{\mathrm{Ca}}$ was fully reversible when the pipette solution returned to the initial 0 GTP-containing internal solution. The stimulatory effect of cGMP was smaller in amplitude than the effect of $50 \mu \mathrm{M}$ cAMP, which produced an approximately twofold increase in $\mathrm{I}_{\mathrm{Ca}}$ (Fig. 6). The effect of 0.5 $\mu \mathrm{M}$ cGMP was examined in a total of 12 similar experiments, as in Fig. 6. In these cells, cGMP increased basal $\mathrm{I}_{\mathrm{Ca}}$ by $80.0 \pm 15.5 \%$. Five of these cells survived a second challenge with $50 \mu \mathrm{M}$ intracellular cAMP which enhanced $\mathrm{I}_{\mathrm{Ca}}$ by $209.1 \pm 65.4 \%$ over its basal amplitude. Thus, cGMP inhibition of PDE3 appears to dominate over cGMP stimulation of PDE2 when exogenous cGMP was introduced in the cytoplasm.

The findings that EHNA and cGMP stimulate basal $\mathrm{I}_{\mathrm{Ca}}$ in human atrial myocytes are somewhat at variance with our earlier findings that cGMP and EHNA have no effect on basal $\mathrm{I}_{\mathrm{Ca}}$ in frog ventricular myocytes. On the contrary, cGMP strongly antagonized the stimulatory effect of isoprenaline or cAMP on $\mathrm{I}_{\mathrm{Ca}}(3,12,13,15)$ in this preparation, and this effect was mediated by PDE2 activation since it was reversed by EHNA (16). To examine whether these differences were a result of tissue 

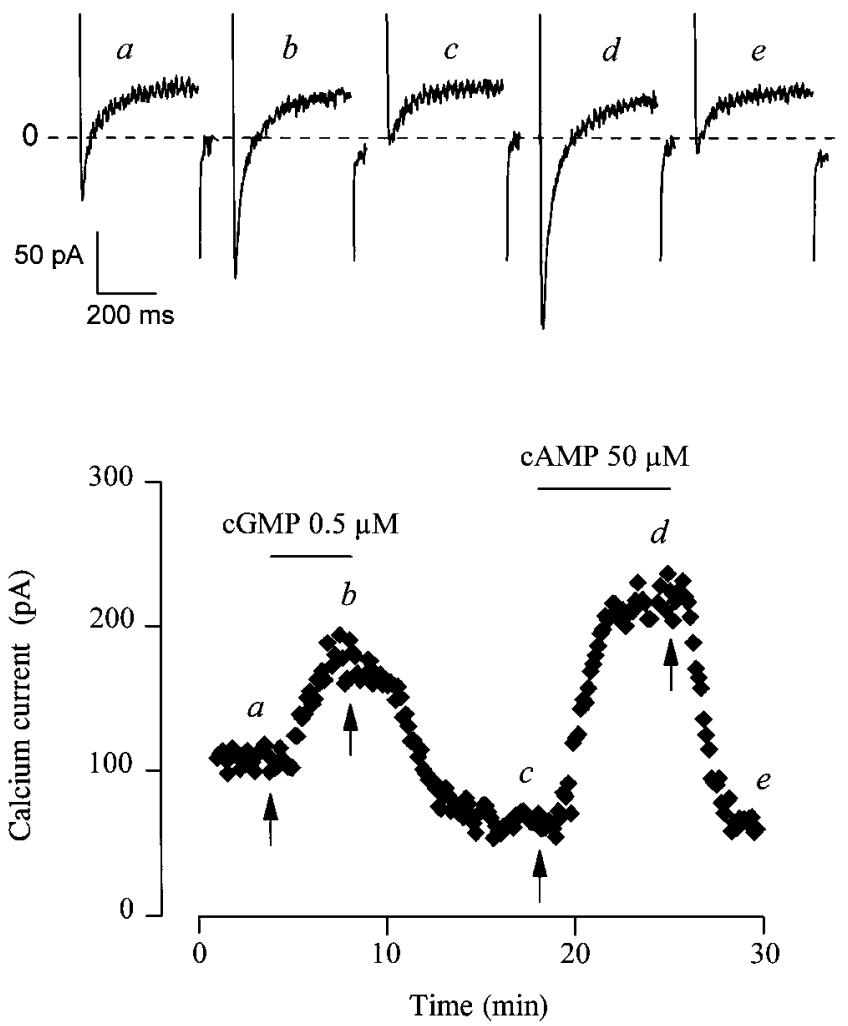

Figure 6. Effects of cGMP and cAMP on basal $\mathrm{I}_{\mathrm{Ca}}$ in human atrial myocytes. Each symbol corresponds to a measure of $\mathrm{I}_{\mathrm{Ca}}$ at $0 \mathrm{mV}$ obtained every $8 \mathrm{~s}$. The cell was superfused with control solution throughout the entire experiment. The cell was initially dialyzed with a 0 GTP-containing internal solution. At the first arrow, the pipette solution was changed to one containing $0.5 \mu \mathrm{M}$ cGMP which produced a clear increase in $\mathrm{I}_{\mathrm{Ca}}$. At the second arrow, the pipette solution returned to the initial 0-GTP solution. At the third arrow, $50 \mu \mathrm{M}$ cAMP was added to the pipette solution which started to dialyze the cell. This produced a large increase in $\mathrm{I}_{\mathrm{Ca}}$ that was reversed when the pipette solution returned to initial 0-GTP solution (last arrow). The individual current traces shown on the upper part were obtained at the times indicated by the corresponding letters in the bottom graph. Dotted line, zero current level.

(atrium versus ventricle) or species (mammalian versus amphibian) differences, we have examined the effect of EHNA on basal $\mathrm{I}_{\mathrm{Ca}}$ in rat ventricular and atrial myocytes. Rat ventricular cells were larger in size than human atrial myocytes and had a threefold higher membrane capacitance $(174.7 \pm 8.9 \mathrm{pF}$, $n=24$, versus $59.6 \pm 4.6 \mathrm{pF}, n=28)$. Under basal conditions, the mean $\mathrm{I}_{\mathrm{Ca}}$ amplitude in rat ventricular myocytes was $915.6 \pm 42.8 \mathrm{pA}$ corresponding to a mean current density of $5.6 \pm 0.5 \mathrm{pA} / \mathrm{pF}$. On the contrary, rat atrial myocytes were somewhat smaller in size than human atrial myocytes and had a slightly lower membrane capacitance $(46.1 \pm 4.9 \mathrm{pF}, n=10)$. Basal $\mathrm{I}_{\mathrm{Ca}}$ amplitude in rat atrial myocytes averaged 127.1 \pm 29.1 $\mathrm{pA}$, corresponding to a mean current density of $2.7 \pm 0.5 \mathrm{pA} / \mathrm{pF}$ $(n=10)$. Fig. $7 A$ shows a typical experiment performed in a rat ventricular myocyte. Three increasing concentrations of EHNA $(0.1,1$, and $10 \mu \mathrm{M})$ were successively tested on the myocyte. As shown, none of the concentrations produced any significant effect on $\mathrm{I}_{\mathrm{Ca}}$. Unlike EHNA, application of $1 \mu \mathrm{M}$ iso-
A

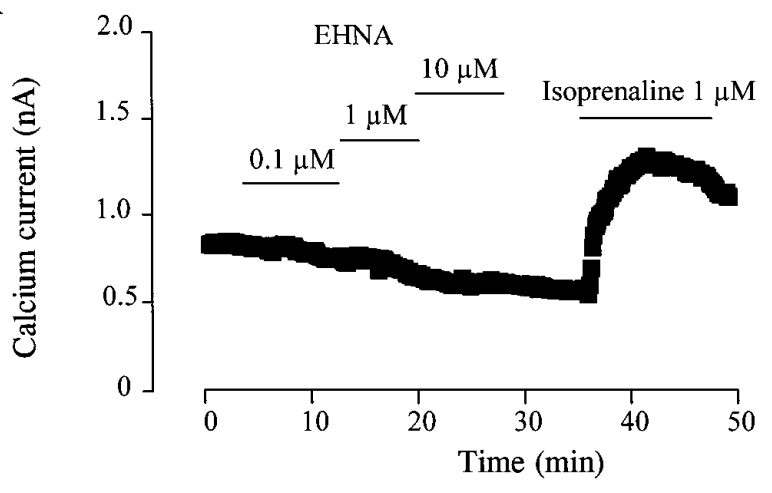

B

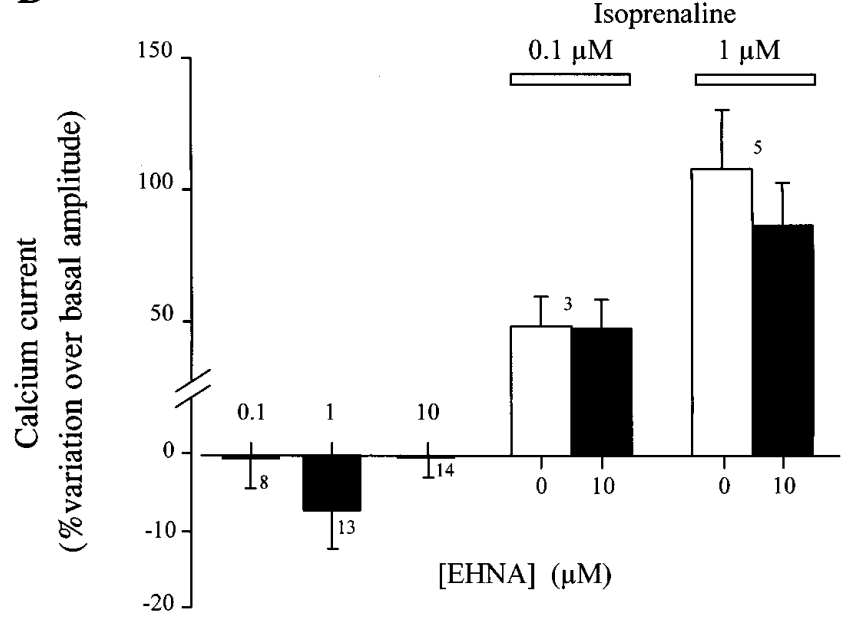

Figure 7. Effects of EHNA and isoprenaline on basal $\mathrm{I}_{\mathrm{Ca}}$ in rat ventricular myocytes. $(A)$ Each symbol corresponds to a measure of $\mathrm{I}_{\mathrm{Ca}}$ at $0 \mathrm{mV}$ obtained every $8 \mathrm{~s}$ in a rat ventricular myocyte. The cell was first superfused with control solution and then exposed to increasing concentrations of EHNA $(0.1,1$, and $10 \mu \mathrm{M})$ or to isoprenaline $(1 \mu \mathrm{M})$ during the periods indicated by the solid lines. (B) Summary of the effects of $0.1,1$, and $10 \mu \mathrm{M}$ EHNA, of 0.1 and $1 \mu \mathrm{M}$ isoprenaline in the absence and presence of $10 \mu \mathrm{M}$ EHNA on basal $\mathrm{I}_{\mathrm{Ca}}$ in rat ventricular myocytes. The bars indicate the mean values and the continuous lines the SEM of the number of experiments indicated near the bars.

prenaline produced a clear stimulation of the current (Fig. 7 $A$ ). Fig. $7 B$ summarizes the results of several similar experiments and shows that none of the three concentrations of EHNA produced a significant effect on basal $\mathrm{I}_{\mathrm{Ca}}$ in rat ventricular myocytes. Intracellular perfusion with cGMP was also shown earlier to have no effect on basal $\mathrm{I}_{\mathrm{Ca}}$ in this preparation (11). On the contrary, isoprenaline $(0.1$ and $1 \mu \mathrm{M})$ produced a clear increase in $\mathrm{I}_{\mathrm{Ca}}$ in these cells. However, as shown in Fig. $7 \mathrm{~B}$, application of EHNA $(10 \mu \mathrm{M})$ to the rat ventricular myocytes in the presence of an intermediate $(0.1 \mu \mathrm{M})$ or saturating $(1 \mu \mathrm{M})$ concentration of isoprenaline also had no effect on $\mathrm{I}_{\mathrm{Ca}}$. The absence of effect of EHNA on basal $\mathrm{I}_{\mathrm{Ca}}$ in rat ventricular myocytes as compared to human atrial myocytes was not because of a tissue difference since EHNA had also no effect on basal $\mathrm{I}_{\mathrm{Ca}}$ in rat atrial myocytes. Indeed, in the presence of 10 and $30 \mu \mathrm{M}$ EHNA, $\mathrm{I}_{\mathrm{Ca}}$ amplitude in rat atrial myocytes was $96.6 \pm 6.2 \%(n=3)$ and $92.8 \pm 3.0 \%(n=7)$ of its basal amplitude, respectively, while 0.1 and $10 \mu \mathrm{M}$ isoprenaline increased 
the current by $65.3 \pm 22.6 \%(n=4)$ and $96.7 \pm 27.2 \%(n=4)$, respectively.

\section{Discussion}

In this study, we examined the effects of EHNA on the highthreshold calcium current $\left(\mathrm{I}_{\mathrm{Ca}}\right)$ in human atrial myocytes and in rat atrial and ventricular myocytes. Several main conclusions can be drawn from our experiments: (a) EHNA produces a stimulation of basal $\mathrm{I}_{\mathrm{Ca}}$ in human atrial myocytes with no modification in the voltage dependence of the Ca current; (b) the maximal stimulatory effect of EHNA on $\mathrm{I}_{\mathrm{Ca}}$ is comparable in amplitude to the maximal effect of isoprenaline, and the two effects are not additive; $(c)$ the effect of EHNA is not a result of adenosine deaminase inhibition; $(d)$ this effect requires the presence of intracellular GTP; $(e)$ intracellular application of cGMP produces a stimulation of $\mathrm{I}_{\mathrm{Ca}}$; and $(f)$ the stimulatory effect of EHNA on basal $\mathrm{I}_{\mathrm{Ca}}$ is not present in rat atrial and ventricular myocytes. We conclude that basal calcium current is controlled by PDE2 activity in human atrial myocytes. The requirement of GTP, the substrate of guanylyl cyclase, for the effect of EHNA, also suggests the presence of a significant basal activity of guanylyl cyclase in these cells.

Since the discovery by Beavo et al. (35) of a stimulatory effect of cGMP on cAMP hydrolysis in various tissues including heart, a lot of information has accumulated on the properties, structure, and amino acid sequence of PDE2 (for review see reference 4). However, although PDE2 is expressed in cardiac myocytes $(4,6)$, relatively little is known on its function. One reason for this is that, until recently, no agent had been described as a selective inhibitor of PDE2 $(4,6)$. The recent findings that EHNA inhibits selectively PDE2 isoform, as far as the soluble PDE isoforms are concerned, in cardiac myocytes $(16,17)$ as well as in other preparations (19-21), opened up the possibility to directly examine the role of this enzyme in the heart. Thus, in this study, we used EHNA to demonstrate a participation of PDE2 in the regulation of basal L-type Ca current in human atrial myocytes.

However, a major drawback in the use of EHNA is that this compound is also a potent inhibitor of adenosine deaminase (18). This raises the possibility that inhibition of adenosine deaminase, possibly via an accumulation of adenosine, may participate in the effects of EHNA. However, for several reasons, we believe that this hypothesis is unlikely. First, adenosine did not mimic the effects of EHNA on basal $\mathrm{I}_{\mathrm{Ca}}$ in our experimental conditions. Moreover, a recent study showed that extracellular application of adenosine inhibits basal $\mathrm{I}_{\mathrm{Ca}}$ in human atrial myocytes (36). This effect is likely mediated by the activation of A1-adenosine receptors which are negatively coupled to adenylyl cyclase. The intracellular accumulation of adenosine upon exposure to EHNA might also affect the regulation of $\mathrm{I}_{\mathrm{Ca}}$. In particular, adenosine could inhibit adenylyl cyclase by binding to the intracellular P-site of the enzyme. However, such an effect would result in an inhibition of $\mathrm{I}_{\mathrm{Ca}}$ which has not been observed with EHNA. Second, it is unlikely that adenosine deaminase is functioning under our experimental conditions, even in the absence of EHNA. Indeed, the $K_{\mathrm{m}}$ of adenosine deaminase for adenosine is in the $20-50 \mu \mathrm{M}$ range (37). Thus, unless adenosine deaminase activity takes place in a compartment not readily available for intracellular perfusion, e.g., in the close vicinity of the membrane, the continuous dialysis of the cell in our whole-cell patch-clamp experiments would prevent such a high accumulation of adenosine within the cell. Third, the cell is also continuously superfused with fresh extracellular solution which does not contain adenosine. This would tend to rapidly dilute from the extracellular surface of the membrane any adenosine that would be released by the cell, hence eliminating a possible activation of membrane adenosine receptors. Finally, inhibition of adenosine deaminase by DCF did not mimic the effect of EHNA on $\mathrm{I}_{\mathrm{Ca}}$ (Fig. 4). Therefore, we conclude that inhibition of adenosine deaminase does not participate, to any significant extent, in the stimulatory effects of EHNA on $\mathrm{I}_{\mathrm{Ca}}$. However, we cannot completely exclude the possibility that adenosine deaminase inhibition may participate in the small inhibitory effect of EHNA observed in the majority of human atrial myocytes perfused without GTP (Fig. 5).

We also examined the possibility that EHNA might have other effects in our preparation, besides the inhibitory effect on PDE2 and adenosine deaminase, which could account for some of the observed effects of EHNA on $\mathrm{I}_{\mathrm{Ca}}$. However, we found that EHNA did not modify the kinetics (Fig. 1) or voltage dependence (Fig. 2) of $\mathrm{I}_{\mathrm{Ca}}$. In addition, EHNA exerted no effect on $\mathrm{I}_{\mathrm{Ca}}$ stimulated by isoprenaline (Fig. 3), which suggests that EHNA does not directly interact with the Ca channels, in their phosphorylated or nonphosphorylated states. In addition to inhibition of adenosine deaminase and PDE2, EHNA has been found to be an inhibitor of dynein ATPase activity, actin assembly, and cell motility $(38,39)$. Although we did not address these questions specifically, it is hard to anticipate how these alternative mechanisms could account for the observed effects of EHNA on $\mathrm{I}_{\mathrm{Ca}}$.

Unlike in human atrial myocytes, EHNA had no effect on basal $\mathrm{I}_{\mathrm{Ca}}$ in frog ventricular myocytes (16) and in rat ventricular and atrial myocytes (Fig. 7). This suggests that PDE2 participates in the basal PDE activity of human atrial myocytes but not in the other animal species tested so far. Species differences were also found for the participation of PDE3. Indeed, we have shown previously using milrinone as a selective inhibitor of PDE3 that this enzyme contributes significantly to the control of the basal amplitude of $\mathrm{I}_{\mathrm{Ca}}$ in human (9) but not in frog $(7,40)$ cardiac myocytes. Thus, in human atrial myocytes, PDE2 and PDE3 participate in the basal PDE activity involved in the regulation of $\mathrm{I}_{\mathrm{Ca}}$. Both enzymes are necessary to maintain low cAMP concentration, since inhibition of one $\mathrm{PDE}$ leads to a large increase in basal $\mathrm{I}_{\mathrm{Ca}}$. An interesting observation comes from our experiments with intracellular application of cGMP. At the cGMP concentration used $(0.5 \mu \mathrm{M})$, PDE3 should be fully inhibited and PDE2 substantially activated (4). However, $\mathrm{I}_{\mathrm{Ca}}$ increased strongly under these conditions (Fig. 6) indicating that cGMP inhibition of PDE3 dominated over cGMP stimulation of PDE2. In other words, cGMP-stimulated PDE2 was insufficient to hydrolyze the basal production of cAMP in human atrial cells when PDE3 was inhibited. This situation is somewhat similar to that found recently in guinea pig ventricular myocytes. In this preparation, intracellular application of cGMP enhanced basal (10) as well as isoprenaline-stimulated $\mathrm{I}_{\mathrm{Ca}}(8,10)$, and this effect was attributed to PDE3 inhibition $(8,10)$. However, this result is at variance with what was found in frog and rat myocytes. Indeed, in both preparations, intracellular perfusion with cGMP had no effect on basal $\mathrm{I}_{\mathrm{Ca}}(3,12,13,15)$. Moreover, cGMP perfusion induced a dramatic inhibitory effect on isoprenaline- or cAMP-stimulated $\mathrm{I}_{\mathrm{Ca}}$ in both preparations $(12,13)$. In frog, this 
effect was because of PDE2 activation since it was antagonized by EHNA (16). However, in rat, this effect was because of activation of cGMP-dependent protein kinase (PKG, 11). PKG also mediated the inhibitory effect of cGMP found in guinea pig myocytes when higher concentrations of cGMP were used, or when PDE3 was blocked by milrinone or $\operatorname{IBMX}(8,10,41)$. These large differences between different animal species in the effect of cGMP and of PDE2 and PDE3 inhibitors on basal and stimulated $\mathrm{I}_{\mathrm{Ca}}$ allowed us to propose in each species a relative order of potency of the three cGMP targets with respect to their modulation of $\mathrm{I}_{\mathrm{Ca}}$ : PDE2 $>$ PDE3 $>>$ PKG in frog $(7,12$, 13); $\mathrm{PDE} 3>\mathrm{PKG}>>$ PDE2 in guinea pig $(8,10,41)$; $\mathrm{PKG}>$ PDE3 $>>$ PDE2 in rat $(11,15)$; PDE3 $>$ PDE2 $>$ PKG in human (9, this study). Further experiments are needed to delineate whether these species differences are a result of differences in protein expression, substrate specificity, maximal enzymatic activity, and/or intracellular localization of the three cGMP-binding proteins. Moreover, at basal, the respective role of each enzyme will also depend on the basal activity of adenylyl cyclase and/or guanylyl cyclase. Interestingly, we found that the stimulatory effect of EHNA disappeared in the absence of intracellular GTP (Fig. 5) suggesting that the activity of PDE2 in human atrial myocytes is itself controlled by the activity of guanylyl cyclase.

It is likely that the respective activities of PDE2 and PDE3 and their localization within the cell will determine the response of the cardiac muscle to various modulators of the cGMP and cAMP cascades. In this respect, there is indirect evidence that PDE2 might be involved in the muscarinic regulation of $\mathrm{I}_{\mathrm{Ca}}$ and contraction in rat and rabbit cardiac myocytes (42-45) but not in guinea pig (46) and frog cardiac myocytes $(47,48)$. Thus, to test this hypothesis directly, it might be interesting to examine whether EHNA is able to antagonize the inhibitory effect of acetylcholine on $\mathrm{I}_{\mathrm{Ca}}$ and contraction in these preparations. These important species differences should also prompt us to examine the participation of PDE2 in the muscarinic regulation of the human heart. Finally, the use of EHNA should allow us to progress in our comprehension of the regulatory role of PDE2 in the function of other cell types and organs and in their responses to various physiological stimuli.

\section{Acknowledgments}

We wish to thank Mr. Patrick Lechêne, Mrs. Florence Lefebvre, and Mrs. Catherine Rücker-Martin for skillful technical assistance, Dr. Pierre-François Méry, Dr. Jorge Kirilovsky, and Dr. Eric Mayoux for helpful discussions, and Dr. Thierry Folliguet, Dr. Patrice Dervanian, Dr. Jean-Yves Neveux, and Dr. Loïc Macé of the Service de Chirurgie Cardiaque, Hôpital Marie Lannelongue, Le Plessis-Robinson, France, for their assistance in obtaining the tissues used in these experiments.

This work was supported by the Institut National pour la Santé et la Recherche Médicale (INSERM CRE 930410), the Association Française contre les Myopathies, the Glaxo Laboratories (France), the Fondation pour la Recherche Médicale, the Ministère de la Recherche et de l'Enseignement Supérieur (ACC-SV9), and the Association Recherche et Partage.

\section{References}

1. Hartzell, H.C. 1988. Regulation of cardiac ion channels by catecholamines, acetylcholine and $2^{\text {nd }}$ messenger systems. Prog. Biophys. Mol. Biol. 52: $165-247$.

2. McDonald, T.F., S. Pelzer, W. Trautwein, and D.J. Pelzer. 1994. Regula- tion and modulation of calcium channels in cardiac, skeletal, and smooth muscle cells. Physiol. Rev. 74:365-507.

3. Hove-Madsen, L., P.-F. Méry, J. Jurevicius, A.V. Skeberdis, and R. Fischmeister. 1996. Regulation of myocardial calcium channels by cyclic AMP metabolism. Basic Res. Cardiol. 91:1-8.

4. Beavo, J.A. 1995. Cyclic nucleotide phosphodiesterases: functional implications of multiple isoforms. Physiol. Rev. 75:725-748.

5. Conti, M., G. Nemoz, C. Sette, and E. Vicini. 1995. Recent progress in understanding the hormonal regulation of phosphodiesterases. Endocr. Rev. 16: 370-389.

6. Stoclet, J.-C., T. Keravis, N. Komas, and C. Lugnier. 1995. Cyclic nucleotide phosphodiesterases as therapeutic targets in cardiovascular diseases. Exp. Opin. Invest. Drugs. 4:1081-1100.

7. Fischmeister, R., and H.C. Hartzell. 1990. Regulation of calcium current by low- $\mathrm{K}_{\mathrm{m}}$ cyclic AMP phosphodiesterases in cardiac cells. Mol. Pharmacol. 38: 426-433.

8. Ono, K., and W. Trautwein. 1991. Potentiation by cyclic GMP of $\beta$-adrenergic effect on calcium current in guinea-pig ventricular cells. J. Physiol. (Lond.). 443:387-404.

9. Kirstein, M., M. Rivet-Bastide, S. Hatem, A. Benardeau, J.-J. Mercadier, and R. Fischmeister. 1995. Nitric oxide regulates the calcium current in isolated human atrial myocytes. J. Clin. Invest. 95:794-802.

10. Shirayama, T., and A.J. Pappano. 1996. Biphasic effects of intrapipette cyclic guanosine monophosphate on L-type calcium current and contraction of guinea pig ventricular myocytes. J. Pharmacol. Exp. Ther. 279:1274-1281.

11. Méry, P.-F., S.M. Lohmann, U. Walter, and R. Fischmeister. 1991. Ca ${ }^{2+}$ current is regulated by cyclic GMP-dependent protein kinase in mammalian cardiac myocytes. Proc. Natl. Acad. Sci. USA. 88:1197-1201.

12. Hartzell, H.C., and R. Fischmeister. 1986. Opposite effects of cyclic GMP and cyclic AMP on $\mathrm{Ca}^{2+}$ current in single heart cells. Nature (Lond.). 323: 273-275.

13. Fischmeister, R., and H.C. Hartzell. 1987. Cyclic guanosine $3^{\prime}, 5^{\prime}$-monophosphate regulates the calcium current in single cells from frog ventricle. $J$. Physiol. (Lond.). 387:453-472.

14. Méry, P.-F., C. Pavoine, L. Belhassen, F. Pecker, and R. Fischmeister. 1993. Nitric oxide regulates cardiac $\mathrm{Ca}^{2+}$ current-involvement of cGMP-inhibited and cGMP-stimulated phosphodiesterases through guanylyl cyclase activation. J. Biol. Chem. 268:26286-26295.

15. Fischmeister, R., and P.-F. Méry. 1996. Regulation of cardiac $\mathrm{Ca}^{2+}$ channels by cGMP and NO. In Molecular Physiology and Pharmacology of Cardiac Ion Channels and Transporters. M. Morad, S. Ebashi, W. Trautwein, and Y. Kurachi, editors. Kluwer Academic Publishers Group, Dordrecht, The Netherlands/Boston/London. 93-105.

16. Méry, P.-F., C. Pavoine, F. Pecker, and R. Fischmeister. 1995. Erythro9-[2-hydroxy-3-nonyl]adenine inhibits cGMP-stimulated phosphodiesterase in isolated cardiac myocytes. Mol. Pharmacol. 48:121-130.

17. Podzuweit, T., P. Nennstiel, and A. Müller. 1995. Isozyme selective inhibition of cGMP-stimulated cyclic nucleotide phosphodiesterases by erythro9-(2-hydroxy-3-nonyl) adenine. Cell. Signalling. 7:733-738.

18. Schaeffer, H.J., and C.F. Schwender. 1974. Enzyme inhibitors. 26. Bridging hydrophobic and hydrophilic regions on adenosine deaminase with some 9-(2-hydroxy-3-alkyl)adenines. J. Med. Chem. 17:6-8.

19. Michie, A.M., M. Lobban, T. Muller, M. Harnett, and M.D. Houslay. 1996. Rapid regulation of PDE-2 and PDE-4 cyclic AMP phosphodiesterase activity following ligation of the $\mathrm{T}$ cell antigen receptor on thymocytes: analysis using the selective inhibitors erythro-9-(2-hydroxy-3-nonyl)-adenine (EHNA) and rolipram. Cell. Signalling. 8:97-110.

20. Suttorp, N., S. Hippenstiel, M. Fuhrmann, M. Krull, and T. Podzuweit. 1996. Role of nitric oxide and phosphodiesterase isoenzyme II for reduction of endothelial hyperpermeability. Am. J. Physiol. (Cell. Physiol.). 270:C778-C785.

21. Haynes, J., D.W. Killilea, P.D. Peterson, and W.J. Thompson. 1996. Erythro-9-(2-hydroxy-3-nonyl)adenine inhibits cyclic-3',5'-guanosine monophosphate-stimulated phosphodiesterase to reverse hypoxic pulmonary vasoconstriction in the perfused rat lung. J. Pharmacol. Exp. Ther. 276:752-757.

22. Zhu Q., X. Tang, M.A. Claydon, G.L. Hicks, Jr., and T. Wang. 1994 Adenosine deaminase inhibitor in cardioplegia enhanced function preservation of the hypothermically stored rat heart. Transplantation (Baltimore). 57:35-40.

23. Xia, Y., G. Khatchikian, and J.L. Zweier. 1996. Adenosine deaminase inhibition prevents free radical-mediated injury in the postischemic heart. $J$. Biol. Chem. 271:10096-10102.

24. Perrella, M.A., T.R. Schwab, B. O'Murchu, M.M. Redfield, C.-M. Wei, B.S. Edwards, and J.C. Burnett, Jr. 1992. Cardiac atrial natriuretic factor during evolution of congestive heart failure. Am. J. Physiol. 262:H1248-H1255.

25. De Belder, A., M.W. Radomski, H.J.F. Why, P.J. Richardson, C.A. Bucknall, E. Salas, J.F. Martin, and S. Moncada. 1993. Nitric oxide synthase activities in human myocardium. Lancet (N. Am. Ed.). 341:84-85.

26. Winlaw, D.S., G.A. Smythe, A.M. Keogh, C.G. Schyvens, P.M. Spratt, and P.S. Macdonald. 1994. Increased nitric oxide production in heart failure. Lancet (N. Am. Ed.). 344:373-374.

27. Rücker-Martin, C., S. Hatem, J. Dubus, L. Mace, J.-L. Samuel, and J.-J. Mercadier. 1993. Behaviour of human atrial myocytes in culture is donor agedependent. Neuromusc. Disord. 3:385-390. 
28. Pucéat, M., O. Clément, P. Lechêne, J.M. Pelosin, R. Ventura-Clapier, and G. Vassort. 1990. Neurohormonal control of calcium sensitivity of myofilaments in rat single heart cells. Circ. Res. 67:517-524.

29. Hamill, O.P., A. Marty, E. Neher, B. Sakmann, and F.J. Sigworth. 1981. Improved patch-clamp techniques for high-resolution current recordings from cell and cell-free patches. Pflügers Arch. Eur. J. Physiol. 391:85-100.

30. Wagner, D.R., F. Bontemps, and G. Vandenberghe. 1994. Existence and role of substrate cycling between AMP and adenosine in isolated rabbit cardiomyocytes under control conditions and in ATP depletion. Circulation. 90:13431349.

31. Tremblay, J., R. Gerzer, and P. Hamet. 1988. Cyclic GMP in cell function. Adv. Sec. Messenger Prot. Phosphoryl. Res. 22:320-383.

32. Waldman, S.A., D.C. Leitman, and F. Murad. 1991. Immunoaffinity purification of soluble guanylyl cyclase. Methods Enzymol. 195:391-396.

33. Legrand, B., E. Deroubaix, J.-P. Couetil, and E. Coraboeuf. 1992. Effects of atrionatriuretic factor on $\mathrm{Ca}^{2+}$ current and $\mathrm{Ca}_{\mathrm{i}}$-independent transient outward $\mathrm{K}^{+}$current in human atrial cells. Pflügers Arch. Eur. J. Physiol. 421: 486-491.

34. Gilman, A.G. 1987. G proteins: transducers of receptor-generated signals. Annu. Rev. Biochem. 56:615-649.

35. Beavo, J.A., J.G. Hardmann, and E.W. Sutherland. 1971. Stimulation of adenosine $3^{\prime}, 5^{\prime}$ monophosphate hydrolysis by guanosine $3^{\prime}, 5^{\prime}$ monophosphate. J. Biol. Chem. 246:3841-3846.

36. Pelzmann, B., P. Schaffer, H. Mächler, B. Rigler, and B. Koidl. 1995. Adenosine inhibits the L-type calcium current in human atrial myocytes. Naunyn-Schmiedeberg's Arch. Pharmacol. 351:293-297.

37. Schrader, W.P., and C.A. West. 1990. Localization of adenosine deaminase and adenosine deaminase complexing protein in rabbit heart. Implications for adenosine metabolism. Circ. Res. 66:754-762.

38. Penningroth, S.M. 1986. Erythro-9-[3-2(hydroxynonyl)]adenine and vanadate as probes for microtubule-based cytoskeletal mechanochemistry. Methods Enzymol. 134:477-483.
39. Schliwa, M., R.M. Ezzell, and U. Euteneuer. 1984. Erythro-9-[3-2(hydroxynonyl)] adenine is an effective inhibitor of cell motility and actin assembly. Proc. Natl. Acad. Sci. USA. 81:6044-6048.

40. Fischmeister, R., and H.C. Hartzell. 1991. Cyclic AMP phosphodiesterases and $\mathrm{Ca}^{2+}$ current regulation in cardiac cells. Life Sci. 48:2365-2376.

41. Levi, R.C., G. Alloatti, and R. Fischmeister. 1989. Cyclic GMP regulates the Ca-channel current in guinea pig ventricular myocytes. Pflügers Archiv. (Eur. J. Physiol.). 413:685-687.

42. Han, X., Y. Shimoni, and W.R. Giles. 1994. An obligatory role for nitric oxide in autonomic control of mammalian heart rate. J. Physiol. (Lond.). 476: 309-314.

43. Han, X., Y. Shimoni, and W.R. Giles. 1995. A cellular mechanism for nitric oxide-mediated cholinergic control of mammalian heart rate. J. Gen. Physiol. 106:45-65.

44. Balligand, J.-L., L. Kobzik, X.Q. Han, D.M. Kaye, L. Belhassen, D.S. Ohara, R.A. Kelly, and T.W. Smith. 1995. Nitric oxide-dependent parasympathetic signaling is due to activation of constitutive endothelial (type III) nitric oxide synthase in cardiac myocytes. J. Biol. Chem. 270:14582-14586.

45. Han, X., L. Kobzik, J.-L. Balligand, R.A. Kelly, and T.W. Smith. 1996. Nitric oxide synthase (NOS3)-mediated cholinergic modulation of $\mathrm{Ca}^{2+}$ current in adult rabbit atrioventricular nodal cells. Circ. Res. 78:998-1008.

46. Zakharov, S.I., S. Pieramici, G.K. Kumar, N.R. Prabhakar, and R.D. Harvey. 1996. Nitric oxide synthase activity in guinea pig ventricular myocytes is not involved in muscarinic inhibition of cAMP-regulated ion channels. Circ. Res. 78:925-935.

47. Jurevicius, J., and R. Fischmeister. 1996. Acetylcholine inhibits $\mathrm{Ca}^{2+}$ current by acting exclusively at a site proximal to adenylyl cyclase in frog cardiac myocytes. J. Physiol. (Lond.). 491:669-675.

48. Méry, P.F., L. Hove-Madsen, J.-M. Chesnais, H.C. Hartzell, and R. Fischmeister. 1996. Nitric oxide synthase does not participate in the negative inotropic effect of acetylcholine in frog heart. Am. J. Physiol. (Heart Circ. Physiol.). 39:H1178-H1188. 